\title{
PENGARUH PRODUCT DAN SERVICE QUALITY PADA CUSTOMER TRUST DAN DAMPAKNYA TERHADAP PURCHASE INTENTION STUDI KASUS: PT.INDOTEHNIK CIPTA SEMBADA
}

\author{
Aryo Bismo \\ Binus Business School Undergradutae Program \\ Bina Nusantara University \\ e-mail : aryo.bismo001@binus.ac.id \\ Yonathan Gunawan \\ Binus Business School Undergradutae Program \\ Bina Nusantara University \\ e-mail : darkrepulsor66@yahoo.com
}

\begin{abstract}
The purpose of this study was to determine the effect of product quality and service quality through customer trust on purchase intention at PT. IndoTehnik Cipta Sembada. The data collection method is using questionnaire that distributed to people who already made a purchase or have an electric panel that sold by PT. Indotehnik Cipta Sembada. The analysis method used on this research is path analysis. The results achieved that service quality and customer trust has relationship while on the other hand there is no relationship between product quality and customer trust another result was there is no relationship between product quality toward purchase intention it is followed by there is no relationship between service quality to purchase intention, and there is no relationship between customers trust in purchase intention indirectly, to conclude, in this case there is only service quality that has significant and positive effect towards customer trust.
\end{abstract}

\begin{abstract}
ABSTRAK
Tujuan dari penelitian ini adalah untuk mengetahui pengaruh product quality dan service quality melalui customer trust terhadap purchase intention di PT. IndoTehnik Cipta Sembada. Metode pengumpulan data adalah dengan menggunakan kuisioner yang disebarkan ke orang - orang yang pernah melakukan pembelian atau memiliki panel listrik yang dijual oleh PT. IndoTehnik Cipta Sembada. Metode analisis yang digunakan adalah path analysis, hasil yang dicapai adalah adanya hubungan antara variable service quality terhadap customer trust, tidak adanya hubungan antara product quality terhadap customer trust, tidak adanya hubungan antara product quality terhadap purchase intention, tidak adanya hubungan antara service quality terhadap purchase intention, dan tidak adanya hubungan antara customer trust terhadap purchase intention.
\end{abstract}

Kata kunci: product quality, service quality, customer trust, purchase intention.

\section{PENDAHULUAN}

Globalisasi telah membuat dunia semakin terintegrasi antar satu sama lain, dengan kemajuan teknologi dalam bidang transportasi, pengiriman barang, dan komunikasi telah mempermudah perusahaan dalam memasarkan produknya ke negara lain, tidak hanya itu hal 


\section{Buletin Ekonomi}

ini juga memberikan kemudahan bagi konsumen dalam membeli produk dan jasa dari pemasar di negara lain.

Dengan adanya globalisasi, perusahaan tidak hanya bersaing dengan perusahaan lokal akan tetapi juga harus bersaing dengan perusahaan asing. Dampak globalisasi ini juga dirasakan oleh industri panel listrik, hal ini dibuktikan dengan munculnya pesaing-pesaing asing (negara luar) yang masuk ke Indonesia dan membuat perkembangan industri panel listrik menjadi melambat.Hal ini terjadi dikarenakan menurunnya jumlah permintaan untuk perusahaan lokal.

Permasalahan yang sering ditemui oleh PT. IndoTehnik Cipta Sembada adalah daya saing harga yang dimiliki oleh pesaing-pesaing di bidang industri yang sama, karena produk yang dihasilkan oleh PT.IndoTehnik berkualitas tinggi maka harga yang diberikan oleh PT.IndoTehnik juga relatif lebih tinggi dibandingkan dengan pesaing. Daya saing harga yang diberikan oleh para kompetitor lebih rendah dibandingkan dengan harga yang diberikan oleh PT. IndoTehnik menurut CEO PT.IndoTehnik Cipta Sembada.

Tujuan yang ingin dicapai dalam penelitian ini adalah untuk mengetahui pengaruh dari product quality dan service quality pada customer trust dan dampaknya terhadap purchase intention pada pt. Indotehnik cipta sembada.

\section{METODE}




\section{Buletin Ekonomi}

Sampel dari penelitian ini adalah orang - orang yang sudah pernah membeli atau memakai produk panel listrik dari PT.IndoTehnik Cipta Sembada. Hal ini dilakukan untuk mengetahui hal - hal apa saja yang mempengaruhi minat pembelian produk panel listrik di PT. IndoTehnik Cipta Sembada.

Data yang digunakan dalam penelitian ini terbagi menjadi dua jenis, yaitu data primer dan data sekunder.Data primer didapatkan melalui kuisioner yang diberikan kepada perusahaan yang telah membeli panel listrik / menggunakan jasa dari PT.IndoTehnik Cipta Sembada. Dan data sekunder yang digunakan adalah data - data yang diperoleh baik melalui keperpustakaan, dan juga dari sumber - sumber lain yang berhubungan dengan penelitian ini.

Penelitian ini menggunakan metode analisis jalur (Path Analysis).Metode ini digunakan untuk menganalisis pola hubungan antar variabel.Dalam penelitian ini alat yang digunakan untuk melakukan pengujian statisik adalah IBM SPSS (Statisikal Package for Social Science) 22.

\section{ANALISIS DAN PEMBAHASAN}

Penelitian ini terbagi menjadi dua analisis sub struktur. Pertama adalah analisis sub struktur 1 yang menjelaskan pengaruh Product Quality (X1) dan Service Quality (X2) terhadap Customer Trust (Y). Kedua adalah analisis sub struktur 2 yang menjelaskan pengaruh Product Quality (X1), Service Quality (X2) dan Customer Trust (Y) terhadap Purchase intention (Z). Persamaan struktur untuk analisa jalur adalah sebagai berikut:

$Y=p Y X 1+p Y X 2+p Y \epsilon 1$

$Z=p Z X 1+p Z X 2+p Z Y+p Z \epsilon 2$

Berikut merupakan gambaran secara keseluruhan pengujian path analysis dalam penelitian ini:

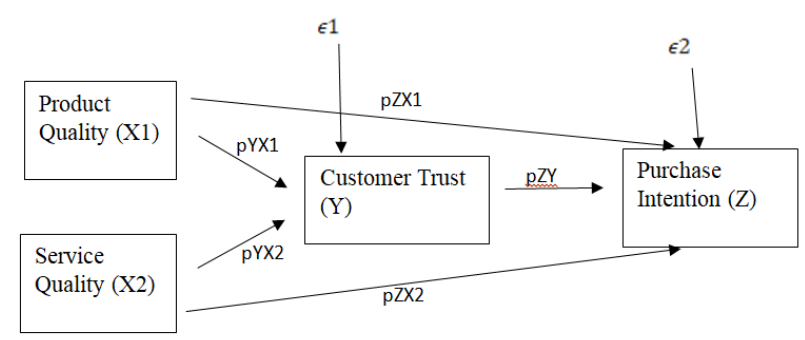

\section{Pengujian Sub - Struktur 1}

Analisis pengaruh Product Quality (X1) dan Service Quality (X2) terhadap Customer Trust (Y) digambarakan sebagai sub - struktur 1 pada gambar berikut ini:

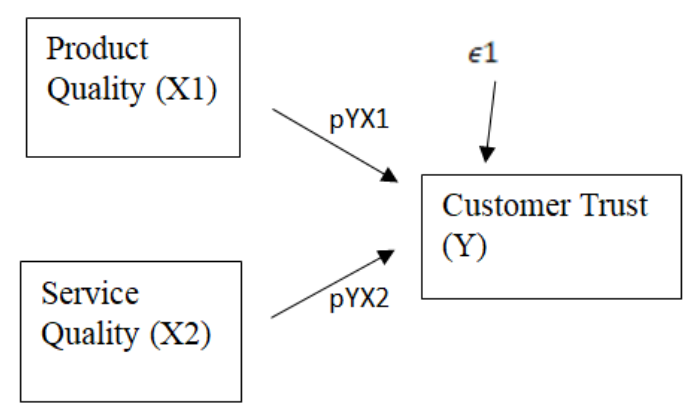




\section{Buletin Ekonomi}

Pengujian sub - struktur 1 ini ditujukan agar dapat diukur pengaruh Product Quality (X1) dan Service Quality (X2) tehadap Customer Trust (Y) panel listrik di PT. IndoTehnik Cipta Sembada. Berikut ini adalah tabel hasil uji sub - struktur 1 dengan bantuan SPSS 22.

\begin{tabular}{|c|c|c|c|c|c|}
\hline \multirow[b]{2}{*}{ Model } & \multicolumn{2}{|c|}{ Unstandardized Coefficients } & \multirow{2}{*}{$\frac{\text { Standardized Coefficients }}{\text { Beta }}$} & & \\
\hline & B & Std. Error & & & $t$ Sig \\
\hline 1 (Constant) & 391 & .260 & & & 503.1 \\
\hline Product_Quality & 101 & 172 & & & 585.5 \\
\hline Service Quality & .821 & 171 & & & 803.000 \\
\hline
\end{tabular}

a. Dependent Variable: Customer_Trust

\section{Hipotesis :}

Ho : Tidak ada pengaruh secara parsial Product Quality dan Service Quality terhadap Customer Trust.

Ha : Ada pengaruh secara parsial Product Quality dan Service Quality terhadap Customer Trust.

\section{Dasar Pengambilan Keputusan :}

Sig $\mathrm{t}-$ hitung $>\alpha$, maka Ho diterima.

Sig $\mathrm{t}-$ hitung $<\alpha$, maka Ho ditolak.

\section{Keputusan :}

Sig t - hitung Product Quality terhadap Customer Trust $=0,561>0,05$, maka Ho diterima.

Sig t - hitung Service Quality terhadap Customer Trust $=0,000<0,05$, maka Ho ditolak.

\section{Kesimpulan :}

Tidak ada pengaruh secara parsial Product Quality terhadap Customer Trust, namun terdapat pengaruh secara parsial Service Quality terhadap Customer Trust.

Berdasarkan Tabel 4.35, dapat dilihat bahwa Tidak ada pengaruh secara parsial Product Quality terhadap Customer Trust, namun terdapat pengaruh secara parsial Service Quality terhadap Customer Trust. Selanjutnya untuk mengetahui besar pengaruh Product Quality dan Service Quality terhadap Customer Trust digunakan R - Square.

Model Summary

\begin{tabular}{|l|c|r|r|r|}
\hline Model & $R$ & R Square & Adjusted R Square & Std. Error of the Estimate \\
\hline 1 & $.857^{\mathrm{a}}$ & .734 & .723 & .33920 \\
\hline
\end{tabular}

a. Predictors: (Constant), Service_Quality, Product_Quality

Nilai R - Square Product Quality dan Service Quality terhadap Customer Trust adalah sebesar 0,734 yang memiliki arti Product Quality dan Service Quality memberikan kontribusi sebesar 73,4\% dan sisanya 26,6 \% atau 0,266 dipengaruhi oleh faktor lain diluar Product Quality dan Service Quality yang tidak diteliti. Berikutnya dihitung besarnya nilai koefisien jalur.

$\rho y \epsilon_{1}=\sqrt{1-R^{2}}=\sqrt{1-0,734}=0,857$

Berikut merupakan tabel kesimpulan dari sub-struktur 1 yang bisa dianalisis secara keseluruhan dalam sub-struktur 1, yaitu Product Quality dan Service Quality terhadap Customer Trust panel listrik di PT. IndoTehnik Cipta Sembada. 


\section{Buletin Ekonomi}

\begin{tabular}{|c|c|c|c|c|c|}
\hline Pengaruh Antar Variabel & $\begin{array}{c}\text { Koefisien Jalur } \\
\text { (Beta) }\end{array}$ & Sig. & $\begin{array}{c}\frac{\text { Pengujian }}{\text { Hipotesis }} \\
\text { Square }\end{array}$ & $\begin{array}{c}\text { Roefisien Variabel } \\
\text { Lainnya }\end{array}$ \\
\hline $\begin{array}{c}\text { Product Quality terhadap } \\
\text { Customer Trust }\end{array}$ & 0,094 & 0,561 & Ho Diterima & 0,734 & 0,857 \\
\cline { 1 - 2 } $\begin{array}{c}\text { Service Quality terhadap } \\
\text { Customer Trust }\end{array}$ & 0,772 & 0,000 & Ho Ditolak & & \\
\hline
\end{tabular}

Setelah melakukan pengujian Path Analysis untuk sub-struktur 1 didapatkan hasil bahwa tidak terdapat pengaruh secara parsial antara Product Quality terhadap Customer Trust sebesar 0,094 serta terdapat pengaruh secara parsial Service Quality terhadap Customer Trust sebesar 0,772. Melalui hasil hitung di tabel koefisien, didapatkan nilai signifikansi t-hitung Product Quality terhadap Customer Trust sebesar 0,561 yang menandakan bahwa Product Quality tidak memiliki pengaruh secara signifikan terhadap Customer Trust, sedangkan nilai signifikansi t-hitung Service Quality sebesar 0,000 yang menandakan bahwa Service Quality memiliki pengaruh secara signifikan terhadap Customer Trust.

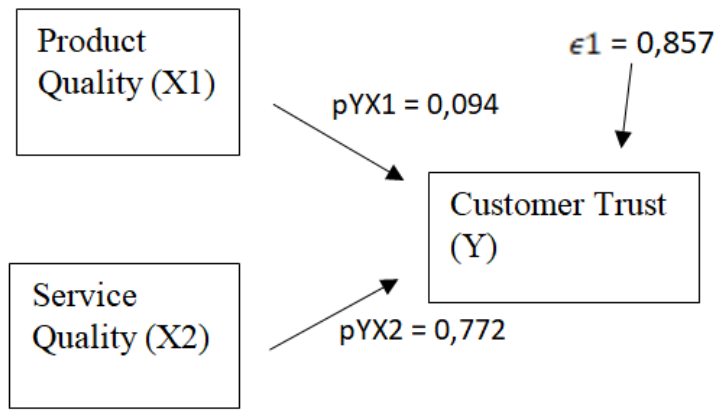

Persamaan Sub-Struktur 1

$Y=p Y X 1+p Y X 2+p Y \epsilon 1$

$Y=0.094+0.772+0.857 \epsilon 1$

Persamaan tersebut dapat menjelaskan bahwa Product Quality berpengaruh terhadap Customer Trust sebesar 0,094 yang artinya apabila Product Quality mengalami kenaikan sebesar 1 satuan, maka nilai Customer Trust akan mengalami kenaikan sebesar 0,094 satuan. Berlaku juga dengan hal sebaliknya, apabila Product Quality mengalami penurunan sebesar 1 satuan, maka nilai Customer Trust akan mengalami penurunan sebesar 0,094 satuan. Service Quality berpengaruh terhadap Customer Trust sebesar 0,772 yang artinya apabila Service Quality mengalami kenaikan sebesar 1 satuan, maka nilai Customer Trust akan mengalami kenaikan sebesar 0,772 satuan. Berlaku juga dengan hal sebaliknya, apabila Service Quality mengalami penurunan sebesar 1 satuan, maka nilai Customer Trust akan mengalami penurunan sebesar 0,772 satuan. Selanjutnya, besarnya R- Square adalah 0,734 atau 73,4\% dan 26,6\% dipengaruhi oleh faktor lain diluar Product Quality dan Service Quality yang tidak diteliti.

Dari hasil analisis membuktikan bahwa ada koefisien jalur yang tidak signifikan yaitu variabel Product Quality (X1), maka Model Sub-Struktur 1 perlu diperbaiki melalui metode trimming, yaitu mengeluarkan variabel Product Quality (X1) yang dianggap hasil dari koefisien jalur tidak signifikan dari analisisnya. Kemudian di uji kembali dengan variabel eksogen Product Quality (X1) tidak diikutsertakan. Hasil perhitungan ditunjukan pada tabel berikut : 


\section{Buletin Ekonomi}

\begin{tabular}{|c|c|c|c|c|c|c|}
\hline \multicolumn{7}{|c|}{ Coefficients ${ }^{a}$} \\
\hline \multirow[b]{2}{*}{ Model } & \multicolumn{2}{|c|}{ Unstandardized Coefficients } & \multirow{2}{*}{\multicolumn{2}{|c|}{\begin{tabular}{|c|} 
Standardized Coefficients \\
Beta
\end{tabular}}} & \multirow[b]{2}{*}{$t$} & \multirow[b]{2}{*}{ Sig. } \\
\hline & B & Std. Error & & & & \\
\hline 1 (Constant) & 421 & 253 & & & 1.663 & .103 \\
\hline Service_Quality & .909 & .079 & & 856 & 11.458 & .000 \\
\hline
\end{tabular}

a. Dependent Variable: Customer_Trust

Model Summaryb

\begin{tabular}{|c|c|c|c|c|}
\hline Model & R & R Square & Adjusted R Square & Std. Error of the Estimate \\
\hline
\end{tabular}

\begin{tabular}{|l|r|r|r|r|}
\hline 1 & $.856^{\mathrm{a}}$ & .732 & .727 & .33687 \\
\hline
\end{tabular}

a. Predictors: (Constant), Service_Quality

b. Dependent Variable: Customer_Trust

Berdasarkan hasil analisis pada tabel diatas diperoleh nilai koefisien jalur X2 terhadap $\mathrm{Y}$ sebesar 0,856 dengan melihat $\mathrm{R}$ - Square pada tabel 4.39, dimana nilai $\mathrm{R}$ - Square adalah 0,732 yang memiliki arti Service Quality memiliki kontribusi sebesar 73,2\% dan sisanya 26,8\% dipengaruhi oleh variabel lain yang tidak diteliti.

Berikut dihitung besarnya nilai koefisien jalur :

$\rho y \epsilon_{1}=\sqrt{1-R^{2}}=\sqrt{1-0,732}=0,518$

Dengan demikian didapat hasil model sub-struktur 1 sesudah Trimming :

$\epsilon 1=0,518$

Service

Quality (X2)

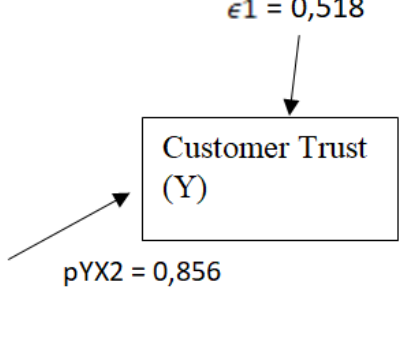

Persamaan Sub-Struktur 1 setelah Trimming :

$Y=p Y X 2+p Y \epsilon 1$

$Y=0,856+0,518 \epsilon 1$

Persamaan tersebut dapat menjelaskan bahwa Service Quality berpengaruh terhadap Customer Trust sebesar 0,856 yang artinya apabila Service Quality mengalami kenaikan sebesar 1 satuan, maka nilai Customer Trust akan mengalami kenaikan sebesar 0,856 satuan. Berlaku juga dengan hal sebaliknya, apabila Service Quality mengalami penurunan sebesar 1 satuan, maka nilai Customer Trustakan mengalami penurunan sebesar 0,856 satuan. Selanjutnya, besarnya R- Square adalah 0,518 atau 51,8,\% dan 48,2\% dipengaruhi oleh faktor lain diluar Service Quality yang tidak diteliti.

\section{Pengujian Sub-Struktur 2}

Analisis pengaruh Product Quality (X1), Service Quality (X2), dan Customer Trust (Y) terhadap Purchase Intention (Z) digambarkan sebagai sub - struktur 2 pada gambar berikut ini:

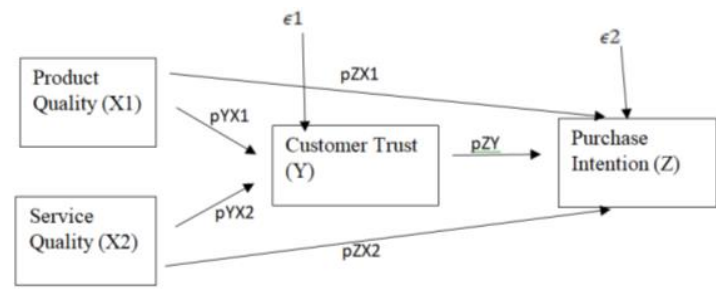




\section{Buletin Ekonomi}

Pengujian sub-struktur 2 ini ditujukan agar dapat diukur pengaruh Product Quality (X1), Service Quality (X2), dan Customer Trust (Y) terhadap Purchase Intention (Z) panel listrik di PT. IndoTehnik Cipta Sembada. Berikut ini adalah tabel hasil uji sub-struktur 2 dengan bantuan SPSS 22.

\begin{tabular}{|l|r|r|r|r|r|}
\hline & \multicolumn{5}{|c|}{ Coefficients $^{\circ}$} \\
\cline { 2 - 5 } Model & \multicolumn{1}{|c|}{ U Standardized Coefficients } & Standardized Coefficients & & \\
\hline 1 (Constant) & -.172 & .404 & Beta & \multicolumn{1}{c}{ Sig. } \\
\hline Product_Quality & .419 & .262 & -.425 & .673 \\
Service_Quality & .238 & .317 & .336 & 1.603 & .116 \\
Customer_Trust & .313 & .221 & .192 & .753 & .455 \\
\hline
\end{tabular}

a. Dependent Variable: Purchase_Intention

\section{Hipotesis :}

Ho : Tidak ada pengaruh secara parsial Product Quality, Service Quality, dan Customer Trust terhadap Purchase Intention.

Ha : Ada pengaruh secara parsial Product Quality, Service Quality, dan Customer Trust terhadap Purchase Intention.

\section{Dasar Pengambilan Keputusan :}

Sig $\mathrm{t}-$ hitung $>\alpha$, maka Ho diterima.

Sig $\mathrm{t}-$ hitung $<\alpha$, maka Ho ditolak.

\section{Keputusan :}

Sig t - hitung Product Quality terhadap Purchase Intention $=0,116>0,05$, maka Ho diterima.

Sig t - hitung Service Quality terhadap Purchase Intention $=0,455>0,05$, maka Ho diterima. Sig t - hitung Customer Trust terhadap Purchase Intention $=0,164>0,05$, maka Ho diterima.

\section{Kesimpulan :}

Tidak ada pengaruh secara parsial Product Quality, Service Quality, Customer Trust terhadap Purchase Intention.

Berdasarkan tabel 4.38 dapat dilihat bahwa tidak terdapat pengaruh secara parsial antara Product Quality, Service Quality, dan Customer Trust terhadap Purchase Intention. Selanjutnya, untuk mengetahui besarnya pengaruh Product Quality, Service Quality, dan Customer Trust terhadap Purchase Intention digunakan R - Square.

Model Summary

\begin{tabular}{|c|c|c|c|c|}
\hline Model & R & R Square & Adjusted R Square & Std. Error of the Estimate \\
\hline & & &
\end{tabular}

a. Predictors: (Constant), Customer_Trust, Product_Quality, Service_Quality

Nilai R - Square Product Quality, Service Quality, dan Customer Trust terhadap Purchase Intention adalah sebesar 0,562 yang artinya Product Quality, Service Quality, dan Customer Trust memberikan konstribusi sebesar 56,2\% dan sisanya 43,8\% atau 0,438 dipengaruhi oleh faktor lain di luar Product Quality, Service Quality, dan Customer Trust yang tidak diteliti. Berikutnya dihitung besarnya nilai koefisien jalur.

$\rho y \epsilon_{2}=\sqrt{1-R^{2}}=\sqrt{1-0.562}=0,662$

Berikut merupakan tabel kesimpulan dari sub-struktur 2 yang bisa dianalisis secara keseluruhan dalam sub-struktur 2, yaitu Product Quality, Service Quality,dan Customer Trust terhadap Purchase Intention panel listrik di PT. IndoTehnik Cipta Sembada. 


\section{Buletin Ekonomi}

\begin{tabular}{|c|l|c|c|c|c|}
\hline Pengaruh Antar Variabel & $\begin{array}{c}\text { Koefisien Jalur } \\
\text { (Beta) }\end{array}$ & Sig. & $\begin{array}{c}\text { Pengujian } \\
\text { Hipotesis }\end{array}$ & $\begin{array}{c}\text { R- } \\
\text { Square }\end{array}$ & $\begin{array}{c}\text { Koefisien } \\
\text { Variabel Lainnya }\end{array}$ \\
\cline { 1 - 4 } $\begin{array}{c}\text { Product Quality terhadap } \\
\text { Purchase Intention }\end{array}$ & 0,336 & 0,116 & Ho Diterima & 0,562 & 0,662 \\
\cline { 1 - 4 } $\begin{array}{c}\text { Service Quality terhadap } \\
\text { Purchase Intention }\end{array}$ & 0,192 & 0,455 & Ho Diterima & & \\
\cline { 1 - 3 } $\begin{array}{c}\text { Customer Trust terhadap } \\
\text { Purchase Intention }\end{array}$ & 0,268 & 0,164 & Ho Diterima & & \\
\cline { 1 - 3 }
\end{tabular}

Setelah melakukan pengujian Product Quality untuk sub-struktur 2 didapatkan hasil bahwa tidak terdapat pengaruh secara parsial antara Product Quality dan Purchase Intention dengan nilai sebesar 0,336. Tidak terdapat pengaruh secara parsial antara Service Quality dan Purchase Intention dengan nilai sebesar 0,192.

Tidak terdapat pengaruh secara parsial antara Customer Trust terhadap Purchase Intention dengan nilai sebesar 0,268. Melalui hasil hitung di table koefisien,didapatkan nilai signifikansi T hitung Product Quality terhadap Purchase Intention sebesar 0,116 yang menandakan bahwa Product Quality memiliki pengaruh yang tidak signifikan terhadap Purchase Intention.

T hitung Service Quality terhadap Purchase Intention sebesar 0,455 yang menandakan bahwa Service Quality memiliki pengaruh yang tidak signifikan terhadap Purchase Intention. T hitung Customer Trust terhadap Purchase Intention sebesar 0,164 yang menandakan bahwa Customer Trust memiliki pengaruh yang tidak signifikan Purchase Intention.

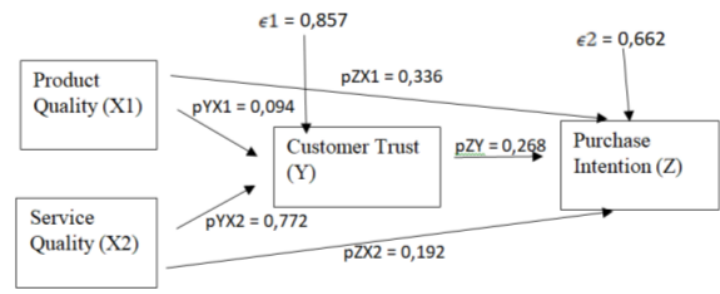

Persamaan Sub - Struktur 2

$Z=p Z X 1+p Z X 2+p Z Y+p Z \epsilon 2$

$Z=0,336+0,192+0,268+0,662 \epsilon 2$

Persamaan tersebut dapat menjelaskan bahwa Product Quality berpengaruhterhadap Purchase Intention sebesar 0,336 yang artinya apabila Product Quality mengalami kenaikkan sebesar 1 satuan, maka nilai Purchase Intention akan mengalami kenaikkan sebesar 0,336 satuan.

Berlaku juga dengan hal sebaliknya, apabila Product Quality mengalami penurunan sebesar 1 satuan, maka nilai Purchase Intention juga akan mengalami penurunan sebesar 0,336 satuan. Service Quality berpengaruh terhadap Purchase Intention sebesar 0,192 yang artinya apabila Service Quality mengalami kenaikan sebesar 1 satuan, maka nilai Purchase Intention akan mengalami kenaikkan sebesar 0,192 satuan.

Berlaku juga dengan hal sebaliknya, apabila Service Quality mengalami penurunan sebesar 1 satuan, maka nilai Purchase Intention juga akan mengalami penurunan sebesar 0,192 satuan. Customer Trust berpengaruh terhadap Purchase Intention sebesar 0,268 yang artinya apabila Customer Trust mengalami kenaikkan sebesar 1 satuan, maka nilai Purchase Intention akan mengalami kenaikkan sebesar 0,268 satuan.

Berlaku juga dengan hal sebaliknya, apabila Customer Trust mengalami penurunan sebesar 1 satuan, maka nilai Purchase Intention juga akan mengalami penurunan sebesar 0,268 satuan. Selanjutnya, besar R - Square adalah 0,562 atau 56,2\% dan sisanya 43,8\% atau 0,438 dipengaruhi oleh faktor lain di luar Product Quality, Service Quality, dan Customer Trust yang tidak diteliti. 


\section{Buletin Ekonomi}

Keseluruhan pengaruh Product Quality, Service Quality dan Customer Trust terhadap Purchase Intention dapat dilihat dalam tabel 4.41

\begin{tabular}{|c|c|c|c|c|}
\hline Pengaruh Antar Variabel & \multirow{2}{*}{ Koefisien Jalur } & \multicolumn{2}{|c|}{ Bentuk Pengaruh } & \multirow{2}{*}{ Total } \\
\cline { 3 - 4 } & & Langsung & Tidak langsung & \\
\hline Product Quality terhadap Customer Trust & 0,094 & 0,094 & - & 0,094 \\
\hline Service Quality terhadap Customer Trust & 0,772 & 0,772 & - & 0,772 \\
\hline Product Quality terhadap Purchase Intention & 0,336 & 0,336 & - & 0,336 \\
\hline Service Quality terhadap Purchase Intention & 0,192 & 0,192 & - & 0,192 \\
\hline Customer Trust terhadap Purchase Intention & 0,268 & 0,268 & - & 0,268 \\
\hline$\epsilon 1$ & 0,336 & 0,336 & - & 0,336 \\
\hline$\epsilon 2$ & 0,662 & 0,662 & - & 0,662 \\
\hline
\end{tabular}

Berdasarkan tabel 4.41, maka dapat ditarik kesimpulan sehingga memberikan informasi secara objektif sebagai berikut:

a) Pengaruh langsung dari total Product Quality terhadap Customer Trust sebesar 0,094

b) Pengaruh langsung dari total Service Quality terhadap Customer Trust sebesar 0,772

c) Pengaruh langsung dari total Product Quality terhadap Purchase Intention sebesar 0,336

d) Pengaruh langsung dari total Service Quality terhadap Purchase Intention sebesar 0,192

e) Pengaruh langsung dari total Customer Trust terhadap Purchase Intention sebesar 0,268

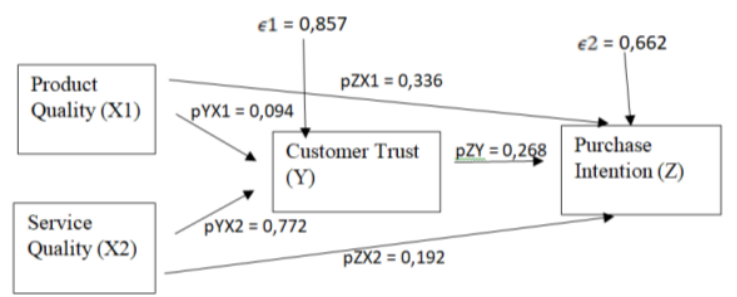

\section{IMPLIKASI HASIL}

Berdasarkan hasil dari penelitian yang telah dilakukan, berikut merupakan hasil-hasil implikasi yang ditemukan untuk menjawab identifikasi masalah dalam penelitian ini.

Tidak terdapat pengaruh secara signifikan dari Product Quality terhadap Customer Trust. Hasil ini dibuktikan dengan nilai signifikan t-hitung sebesar 0,561>0,05 dan nilai pengaruh sebesar 0,094. Hasil penelitian ini membuktikan bahwa Product Quality yang baik akan meningkatkan Customer Trust, dan juga sebaliknya Product Quality yang buruk akan menurunkan Customer Trust.

Menurut peneliti dari hasil analisis Product Quality terhadap Customer Trust tidak berpengaruh secara signifikan dikarenakan tidak semua responden merasa puas dengan kualitas panel listrik yang diproduksi oleh PT. IndoTehnik Cipta Sembada, berdasarkan data tersebut maka PT. IndoTehnik Cipta Sembada harus berusaha meningkatkan kualitas produk yang diproduksinya yaitu panel listrik agar kepercayaan pelanggan terhadap produk yang dijual oleh PT. IndoTehnik Cipta Sembada semakin meningkat. Contoh nyatanya adalah PT. IndoTehnik Cipta Sembada dapat menginvestasi mesin pembuat panel yang otomatis dalam pembuatan panel-panel agar yang dihasilkan lebih baik dan akurat.

Terdapat pengaruh secara signifikan dari Service Quality terhadap Customer Trust. Hasil ini dibuktikan dengan nilai signifikan t-hitung sebesar $0,000<0,05$ dan nilai pengaruh sebesar 0,772. Hasil penelitian ini membuktikan bahwa Service Quality yang baik akan meningkatkan Customer Trust, dan juga sebaliknya Service Quality yang buruk akan menurunkan Customer Trust. 


\section{Buletin Ekonomi}

Menurut peneliti dari hasil analisis Service Quality terhadap Customer Trust berpengaruh secara signifikan dikarenakan PT. IndoTehnik Cipta Sembada memberikan pelayanan kepada konsumen secara baik sehingga pelangan percaya terhadap panel listrik yang dijual oleh PT. IndoTehnik Cipta Sembada, Berdasarkan data tersebut maka PT. IndoTehnik Cipta Sembada harus meningkatkan kualitas pelayanan yang diberikan kepada pelanggan agar kepercayaan pelanggan terhadap penjualan yang dilakukan oleh PT. IndoTehnik Cipta Sembada semakin meningkat. Contoh nyatanya, PT. IndoTehnik Cipta Sembada mengirimkan teknisi-teknsisi untuk mengikuti latihan dan seminar yang diadakan oleh importir peralatan dan asosiasi kelistrikan Indonesia.

Tidak terdapat pengaruh secara signifikan dari Product Quality terhadap Purchase Intention. Hasil ini dibuktikan dengan nilai signifikan t-hitung sebesar 0,116>0,05 dan nilai pengaruh sebesar 0,336. Hasil penelitian ini membuktikan bahwa Product Quality yang baik akan meningkatkan Purchase Intention, dan juga sebaliknya Product Quality yang buruk akan menurunkan Purchase Intention.

Menurut peneliti dari hasil analisis Product Quality terhadap Purchase Intention tidak berpengaruh secara signifikan dikarenakan variabel-variabel lain yang tidak diteliti di dalam penelitian ini, Berdasarkan data tersebut maka PT. IndoTehnik Cipta Sembada harus meningkatkan kualitas produknya agar keinginan pembelian yang dimiliki oleh pelanggan meningkat. Contoh nyatanya adalah PT. IndoTehnik Cipta Sembada dapat menginvestasi mesin pembuat panel yang otomatis dalam pembuatan panel-panel agar yang dihasilkan lebih baik dan akurat.

Tidak terdapat pengaruh secara signifikan dari Service Quality terhadap Purchase Intention. Hasil ini dibuktikan dengan nilai signifikan t-hitung sebesar 0,455 > 0,05 dan nilai pengaruh sebesar 0,192. Hasil penelitian ini membuktikan bahwa Service Quality yang baik akan meningkatkan Purchase Intention, dan juga sebaliknya Service Quality yang buruk akan menurunkan Purchase Intention.

Menurut peneliti dari hasil analisis Service Quality terhadap Purchase Intention tidak berpengaruh secara signifikan dikarenakan variabel kualitas pelayanan tidak berpengaruh besar terhadap minat pembelian konsumen, Berdasarkan data tersebut maka PT. IndoTehnik Cipta Sembada harus meningkatkan kualitas pelayanan yang diberikan kepada pelanggan agar dapat meningkatkan keinginan pelanggan untuk membeli produk yang dijual oleh PT. IndoTehnik Cipta Sembada. Contoh nyatanya, PT. IndoTehnik Cipta Sembada mengirimkan teknisi-teknsisi untuk mengikuti latihan dan seminar yang diadakan oleh importir peralatan dan asosiasi kelistrikan Indonesia.

Tidak terdapat pengaruh secara signifikan dari Customer Trust terhadap Purchase Intention. Hasil ini dibuktikan dengan nilai signifikan t-hitung sebesar 0,164>0,05 dan nilai pengaruh sebesar 0,268. Hasil penelitian ini membuktikan bahwa Customer Trust yang baik akan meningkatkan Purchase Intention, dan juga sebaliknya Customer Trust yang buruk akan menurunkan Purchase Intention.

Menurut peneliti dari hasil analisis Service Quality terhadap Purchase Intention tidak berpengaruh secara signifikan dikarenakan kepercayaan konsumen bukan hanya salah satu variabel yang mempengaruhi minat pembelian konsumen dan masih ada variabel-variabel lain yang mempengaruhi minat pembelian yang tidak di teliti di penelitian ini. Berdasarkan data tersebut maka PT. IndoTehnik Cipta Sembada harus meningkatkan kepercayaan yang dimiliki oleh para pelanggannya agar pelanggan memiliki keinginan untuk membeli yang lebih terhadap produk yang dijual oleh PT. IndoTehnik Cipta Sembada. Contoh nyatanya, PT. IndoTehnik dapat menggunakan simulasi-simulasi nyata dalam proses pemasaran selain presentasi-presentasi yang telah dilakukan. 


\section{Buletin Ekonomi}

\section{KESIMPULAN DAN SARAN}

Berdasarkan hasil penelitian mengenai analisis pengaruh Product Quality dan Service Quality pada Customer Trust dan dampaknya terhadap Purchase Intention panel listrik di PT. IndoTehnik Cipta Sembada, maka diperoleh kesimpulan sebagai berikut :

1. Hipotesis pertama, Ha ditolak, tidak terdapat pengaruh antara Product Quality terhadap Customer Trust panel listrik di PT. IndoTehnik Cipta Sembada.

2. Hipotesis kedua, Ha diterima, terdapat pengaruh antara Service Quality terhadap Customer Trust panel listrik di PT. IndoTehnik Cipta Sembada.

3. Hipotesis ketiga, Ha ditolak, tidak terdapat pengaruh antara Product Quality terhadap Purchase Intention panel listrik di PT. IndoTehnik Cipta Sembada.

4. Hipotesis keempat, Ha ditolak, tidak terdapat pengaruh antara Service Quality terhadap Purchase Intention panel listrik di PT. IndoTehnik Cipta Sembada.

5. Hipotesis kelima, Ha ditolak, tidak terdapat pengaruh antara Customer Trust terhadap Purchase Intention panel listrik di PT. IndoTehnik Cipta Sembada.

\section{Saran}

Dengan memperhatikan hasil analisis dan kesimpulan dari penelitian ini, maka saran peneliti untuk PT. IndoTehnik Cipta Sembada adalah sebagai berikut:

1. Kualitas pelayanan yang dimiliki oleh PT. IndoTehnik Cipta Sembada memiliki nilai kepercayaan konsumen tersendiri. Saran peneliti kepada PT. IndoTehnik Cipta Sembada adalah meningkatkan kualitas pelayanan kepada para konsumen sehingga konsumen lebih percaya terhadap produk yang dijual oleh PT. IndoTehnik Cipta Sembada.

2. Di Indonesia, khususnya Jakarta yang merupakan ibukotanya dipenuhi oleh bangunanbangunan yang mengunakan listrik. Dari situ akan ada banyak konsumen yang membutuhkan panel listrik untuk dipakai di dalam bangunannya. Maka, PT. IndoTehnik Cipta Sembada harus meningkatkan kualitas produk maupun pelayanannya agar konsumen merasa percaya dan nyaman terhadap panel listrik yang dijual oleh PT. IndoTehnik CIpta Sembada.

3. PT. IndoTehnik Cipta Sembada perlu mengetahui faktor-faktor lain yang membuat konsumen ingin membeli panel listrik., peneliti menyarankan untuk terus mencari informasi-informasi mengenai faktor apa saja yang mempengaruhi keputusan pembelian panel listrik dan mencoba untuk menginterpretasikannya kedalam produk panel listrik yang dijual.

\section{Saran untuk peneliti lain}

1. Menggunakan atau menambahkan variabel-variabel yang lain di luar penelitian ini agar mendapatkan hasil yang baru di penelitian yang selanjutnya.

2. Menambahkan jumlah responden yang lebih banyak, agar mendapatkan hasil yang lebih baik di penelitian yang selanjutnya.

Melakukan penelitian di perusahaan yang memproduksi produk yang berbeda agar semakin luas pustaka penelitian di bidang manufaktur.

\section{DAFTAR PUSTAKA}

Anderson, J. C. \& Narus, J. A. (1990). A Model of Distributor Firm and Manufacturer FirmWorking Partnerships, Journal of Marketing, Vol. 54.

Assauri, S. (2004).Manajemen Pemasaran. Jakarta, Rajawali Press.

Azwar, S. (2007). Metode Penelitian. Pustaka.Yogyakarta. 


\section{Buletin Ekonomi}

Chowdury, S R. (2017). Measuring Relationship Between Product Quality Dimensions \& Repurchase Intention of Smart Phone: A Case Study On Chittagong City. International Journal of Scientific \& Engineering Research, Vol. 8, Issue 2.

Cravens, D. W; Piercy\&Nigel.F. (2013), Strategic Marketing 10thEdition. New York: McGraw-Hill International Edition.

Effendy\& Kunto. (2013). Pengaruh Customer Value Proposition Terhadap MinatBeli Konsumen Pada Produk Consumer Pack Premium Baru Bogasari.

Engel, F J; Roger, D B; Paul W M. (2004).Perilaku Konsumen. Jakarta, Binarupa Aksara.

Eri Besra, Dwi Kartini, Meydia Hassan. (2015). The Role of Retail Image and Customer Trust on Purchase Intention of Private Label Product. International Journal of Scientific \& Technology Research, Vol 4 Issue 5, May.

Gregg, Dawn.\& Steven, W. (2010). The relationship between website quality,trust and price premiums at online auctions. Electron Commerces, Vol. 10.

Grewal, D \& Levy, M. (2010). Marketing 2nd edition.McGraw Hill. New York.

Hasibuan, M. (2008).Manajemen Dasar, Pengertian, Dan Masalah. Jakarta, PT. Bumi Aksara

Hawkins, D.I. dan Mothersbaugh, D.L. (2010), Consumer Behavior BuildingMarketing Strategy, 11th edition. New York: The McGraw-Hill Companies,Inc.

Kotler, P. (2002). Manajemen Pemasaran, Edisi Millenium. Jakarta, PT. Prenhallindo.

Kotler, P. (2008). Manajemen Pemasaran Edisi 12. Jakarta.

Kotler, P. (2011). Manajemen Pemasaran di Indonesia : Analisis, Perencanaan, Implementasi, dan Pengendalian. Jakarta, Salemba Empat.

Kotler, Philip. \& Gary Armstrong. (2013). Prinsip-prinsip Pemasaran Edisi 12.Erlangga.

Kotler, Philip. \& Gary Armstrong. (2014). Principle Of Marketing, 15th edition. New Jersey, Pearson Prentice Hall

Kotler, P. \& Keller, K L. (2009).Manajemen PemasaranEdisi 13. Jakarta, Erlangga.

Kotler, P. \& Keller, K L. (2011).Marketing Management 14th Edition.Pearson Education.

Kotler, P. \& Keller, K L. (2016).Marketing Management 16th Edition. New Jersey, Pearson Education.

Mohd Rizaimy Shaharudin, Suhardi Wan Mansor, Anita Abu Hassan, Maznah Wan Omar, Etty Harniza Harum. (2011). The Relationship between Product Quality and Purchase Intention : The Case of Malaysia's National Motorcycle/Scooter Manufacturer. African Journal of Business Management, Vol 5(20). 


\section{Buletin Ekonomi}

Moorman, Christine, Rohit Deshpande, dan Gerald Zaltman. (1993). FactorsAffecting Trust in Market Research Relationships. Journal of Marketing.Vol 57.

Muhammad Arslan. (2014). Impact of Brand Image and Service Quality on Consumer Purchase Intention : A Study of Retail Store in Pakistan. Research on Humanities and Social Sciences, Vol 4, No. 22.

Payne, A. (2008). The Essense of Service Marketing Pemasaran Jasa. Prentice Hall.Essence of Management Series.

Perreault, JR \& McCarthy (2008).Pemasaran Dasar : Pendekatan Manajerial Global Edisi 16. Jakarta, Salemba Empat.

Peter Halim, Bambang Swasto, Djamhur Hamid, M. Riza Firdaus. (2014). The Influence of Product Quality, Brand Image, and Quality of Service to Customer Trust and Implication on Customer Loyalty (Survey on Customer Brand Sharp Electronics Product at the South Kalimantan Province). European Journal of Business and Management, Vol 6 no 29

Richard Chinomona. (2013). The Impact of Product Quality on Percieved Value, Trust, and Students Intention to Purchase Electronic Gadgets.Mediterranean Journal of Social Sciences, Vol 4, No. 14.

Riduwan (2005).Rumus dan Data dalam Aplikasi Statistika. Bandung, Alfabeta.

Robbins, S P. dan Judge, T A. (2008). Organizational Behaviour. Jakarta, Salemba Empat.

Singh, Jagdip, and Deepak Sirdeshmukh. (2000). Agency and Trust Mecanism inconsumer satisfaction and loyalty Judgement.Journal of the Academy ofMarketing Science. Vol 28 No.1.

Sari, D \& Kusuma, B. (2014). Does Luxury Brand Perception Matter in Purchase Intention? A Comparison Between A Japanese Brand and German Brand. Asean Marketing Journal, Vol 4, No 1.

Siagian, Sondang P. (2010). Manajemen Sumber Daya Manusia Edisi 18. Jakarta. PT. Bumi Aksara.

Sugiyono. (2015). Metode Penelitian Pendidikan (Pendekatan Kuantitatif,Kualitatif dan $R \& D)$.Bandung, CV. Alfabeta.

Swastha, B. (2009). Manajemen Penjualan. Yogyakarta, BPFE.

Tjiptono, F (2007). Strategi Pemasaran Edisi 2. Yogyakarta, Andi.

Tjiptono, F. (2008).Strategi Pemasaran Edisi 3. Yogyakarta, Andi Offset.

Tjiptono, F. (2011).Pemasaran Jasa. Malang, Bayumedia. 


\section{Buletin Ekonomi}

Tjiptono, F. (2012).Pemasaran Jasa. Yogyakarta, Andi Offset.

Tjiptono, F. \& Chandra, G. (2012).Pemasaran Strategik Edisi 2, Yogyakarta, Andi.

Zeithaml, Bitner, dan Gremler. (2009). Service Marketing: Integrating CustomerFocus Across the Firm. 